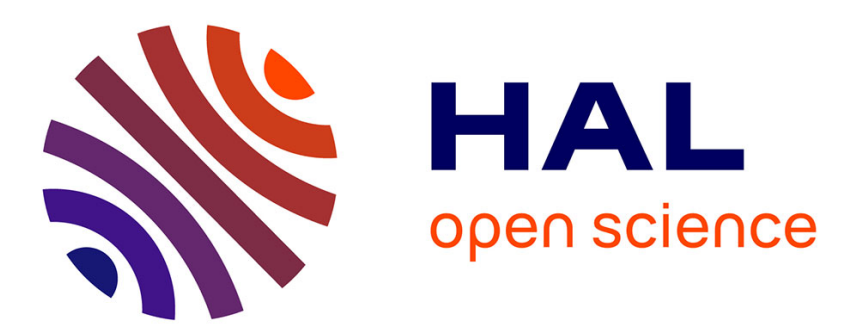

\title{
An analytical approximation for the I-V characteristic of the MISS device
}

\author{
J. Millán, F. Serra-Mestres, X. Aymerich-Humet
}

\section{To cite this version:}

J. Millán, F. Serra-Mestres, X. Aymerich-Humet. An analytical approximation for the I-V characteristic of the MISS device. Revue de Physique Appliquée, 1982, 17 (7), pp.401-404. 10.1051/rphysap:01982001707040100 . jpa-00245013

\section{HAL Id: jpa-00245013 https://hal.science/jpa-00245013}

Submitted on 1 Jan 1982

HAL is a multi-disciplinary open access archive for the deposit and dissemination of scientific research documents, whether they are published or not. The documents may come from teaching and research institutions in France or abroad, or from public or private research centers.
L'archive ouverte pluridisciplinaire HAL, est destinée au dépôt et à la diffusion de documents scientifiques de niveau recherche, publiés ou non, émanant des établissements d'enseignement et de recherche français ou étrangers, des laboratoires publics ou privés. 


\title{
An analytical approximation for the $I-V$ characteristic of the MISS device $\left(^{*}\right)\left({ }^{*}\right)$
}

\author{
J. Millán, F. Serra-Mestres and X. Aymerich-Humet \\ Departamento de Electricidad y Electrònica, Universidad Autònoma de Barcelona, Bellaterra, Barcelona, Spain
}

(Reçu le 22 septembre 1981, révisé le 29 mars 1982, accepté le 8 avril 1982)

\begin{abstract}
Résumé. - Dans ce travail on obtient une expression analytique valable pour la caractéristique $I-V$ du dispositif MISS. Les équations du mécanisme de commutation tiennent compte de la conduction par effet résonnant à travers l'isolant. On déduit aussi le courant et la tension à la commutation.
\end{abstract}

\begin{abstract}
A closed-form expression for the $I-V$ characteristic of the MISS device is obtained from the equations that govern the switching mechanism by considering resonant tunnelling conduction through the insulator. Both switching current and voltage are also obtained.
\end{abstract}

1. Introduction. - The switching mechanism in Metal-Thin $\mathrm{SiO}_{2}-\mathrm{Si}$ ( $\mathrm{n}$ or $\mathrm{p}$ )-Si $\left(\mathrm{p}^{+}\right.$or $\mathrm{n}^{+}$) (MISS) has been analysed by several authors $[1,2]$. The switching in their structures is due to the punch-through mechanism (the depletion layer of the MIS diode goes up to the p-n depletion layer) for low epitaxial doping $\left(N_{\mathrm{E}}\right)$, whereas the avalanche is responsible for the switching in case of high $N_{\mathrm{E}}$. Sarrabayrouse [3], Habib [4, 5], Adan [6] and ourselves [7] have set up regenerative models which account qualitatively for the $I-V$ characteristic. In these models current through the insulator is supported by a direct tunnelling conduction. However, experimental results $[8,10]$ show a current excess that is only explicable if one considers insulator thickness $(\delta)$ much smaller than the measured one.

2. Regenerative model formulation with resonant tunnelling conduction. - In order to explain the discrepancy between the observed current and the one deduced from the regenerative models involving direct tunnelling conduction, we have developed a model [11] based on the resonant tunnelling conduction which is supported by traps existing in the insulator at different energy levels.

In the following we describe the equations that govern the switching mechanism, to obtain an analytical expression for the $j-V$ characteristic.

${ }^{*}$ ) Work performed under the auspices of the « Comisión Asesora Científica y Técnica ".

$\left.{ }^{* *}\right)$ Communication présentée à l'ESSDERC 1981.
When resonant tunnelling conduction through the insulator is considered, the current densities of electrons and holes can be expressed by [12] :

$$
\begin{aligned}
j_{\mathrm{n}}=C_{\mathrm{n}} N_{\mathrm{T}} \exp \left(-\frac{\beta}{2} \chi_{\mathrm{n}}^{1 / 2} \delta\right) & \exp \left(u_{\mathrm{s}}-u_{\mathrm{n}}\right) \times \\
& \times\left\{\exp \left(u_{\mathrm{M}}\right)-1\right\}
\end{aligned}
$$

and

$$
\begin{array}{r}
j_{\mathrm{p}}=C_{\mathrm{p}} N_{\mathrm{T}} \exp \left(-\frac{\beta}{2} \chi_{\mathrm{p}}^{1 / 2} \delta\right) \exp \left(u_{\mathrm{n}}-E_{\mathrm{G}} / k T\right) \times \\
\exp \left(\xi_{\mathrm{s}}-u_{\mathrm{s}}\right)\left\{1-\exp \left(-u_{\mathrm{M}}-\xi_{\mathrm{s}}\right)\right\}
\end{array}
$$

where $C_{\mathrm{n}}\left(C_{\mathrm{p}}\right)$ depends on the structure parameters and is practically independent of the bias voltage $\left(C_{\mathrm{n}} \simeq 9 \times 10^{-12} \mathrm{~A} . \mathrm{cm}\right.$ and $C_{\mathrm{p}} \simeq 5 \times 10^{-12} \mathrm{~A} . \mathrm{cm}$ for $N_{\mathrm{E}}=5 \times 10^{15} \mathrm{~cm}^{-3}$ and $\left.\delta=30 \AA\right): N_{\mathrm{T}}$ is the insulator trap density; $\beta=1.025(\mathrm{eV})^{-1 / 2}(\AA)^{-1}$ and $\chi_{\mathrm{n}(\mathrm{p})}$ is the effective barrier for electrons (holes), when the two bands model is considered $\chi_{\mathrm{n}}=0.80 \mathrm{eV}$ and $\chi_{\mathrm{p}}=0.84 \mathrm{eV}$. The potentials (normalized to $k T / q)$ are represented in figure 1.

All the electrons, injected into the base (semiconductor epitaxial layer) through the insulator by means of the resonant tunnelling conduction, reach the p-n junction when the recombination process is neglected. The p-n junction, in turn, injects into the base a hole current which is $\gamma$ times the electron current, $\gamma$ being the injection factor at the $p-n$ junction. The hole current reaches the $\mathrm{SiO}_{2}-\mathrm{Si}$ interface and flows through the insulator by resonant tunnel. The diffe- 


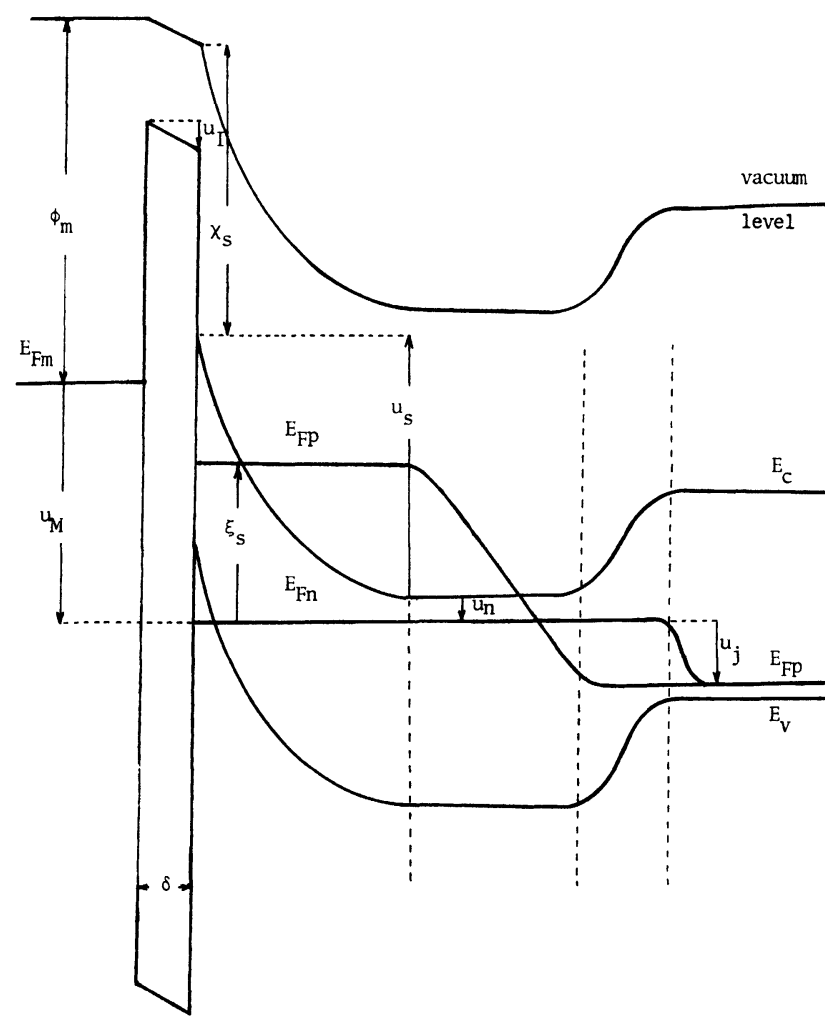

Fig. 1. - Energy diagram of the MISS structure in the high-impedance state.

rence between the metal and hole Fermi levels $\left(E_{\mathrm{FM}}\right.$ and $E_{\mathrm{FP}}$ ) (see Fig. 1) allows the flow of holes through the $\mathrm{SiO}_{2}$ layer.

As the applied voltage increases, the electron barrier decreases with it and the electron current which reaches the p-n junction grows. Consequently, the hole current injected from the p-n junction to the $\mathrm{SiO}_{2}-\mathrm{Si}$ interface also grows given rise to a progressively strong inversion of this interface and a lowering of the electron barrier. This mechanism is responsible for the regenerate process [3].

In order to maintain the charge neutrality of the structure a decrease of the base depletion layer is necessary, therefore, voltage across the structure is reduced after switching.

According to this qualitative behaviour of the switching mechanism, the neutrality equation is essential to determine the switching point. When we consider neither electrostatic influence of the surface states nor charges in the insulator, the MIS charge neutrality equation is written as

$$
\frac{\delta}{L_{\mathrm{D}}} \frac{\varepsilon_{\mathrm{s}}}{\varepsilon_{\mathrm{I}}} \frac{u_{\mathrm{s}}}{\left|u_{\mathrm{s}}\right|} F\left(u_{\mathrm{s}}, \xi_{\mathrm{s}}\right)+u_{\mathrm{I}}=0
$$

where $L_{\mathrm{D}}$ is the extrinsic Debye's length ; $\varepsilon_{\mathrm{s}}\left(\varepsilon_{\mathrm{I}}\right)$ is the semiconductor (insulator) permittivity and $F\left(u_{\mathrm{s}}, \xi_{\mathrm{s}}\right)$ represents the $F$-function for the MIS structure in case of non-equilibrium [13].
The feedback equation is

$$
j_{\mathrm{p}}=\gamma j_{\mathrm{n}}
$$

and the total current density is expressed by

$$
j=j_{\mathrm{n}}+j_{\mathrm{p}} .
$$

The expressions of the normalized potentials for the MIS diode $\left(u_{\mathrm{M}}\right)$ and for the device $\left(u_{\mathrm{A}}\right)$ are deduced from the MISS energy diagram (Fig. 1); their equations are :

$$
u_{\mathrm{M}}=u_{\mathrm{I}}+u_{\mathrm{n}}-\psi_{\mathrm{ms}}-u_{\mathrm{s}}
$$

and

$$
u_{\mathrm{A}}=u_{\mathrm{M}}+u_{\mathrm{j}}
$$

where $\psi_{\mathrm{ms}}=\phi_{\mathrm{ms}} / k T=\left(\phi_{\mathrm{m}}-\chi_{\mathrm{s}}\right) / k T$ and $u_{\mathrm{j}}$ is the normalized potential across the $\mathrm{p}$-n junction.

3. The $j-V$ characteristic. - From the formulation of the resonant tunnelling model described in the last section, one can deduce an approximated expression of the $j-V$ characteristic.

It is known that, in order to observe the switching mechanism, the structure has to be biased so that the MIS diode be reversed-biased whereas the $p-n$ junction remains forward-biased. In this case $u_{\mathrm{M}}$ and $u_{\mathrm{M}}+\xi_{\mathrm{s}}$ are much greater than unity; therefore, from (1), (2), (4) and (5) we obtain,

and

$$
j=j_{\mathrm{AO}} \exp \left(u_{\mathrm{s}}+u_{\mathrm{M}}\right)
$$

where

$$
j=j_{\mathrm{BO}} \exp \left(\xi_{\mathrm{s}}-u_{\mathrm{s}}\right)
$$

$j_{\text {AO }}=(1+\gamma) C_{\mathrm{n}} N_{\mathrm{T}} \exp \left(-\frac{\beta}{2} \chi_{\mathrm{n}}^{1 / 2} \delta\right) \exp \left(-u_{\mathrm{n}}\right)$ and

$$
\begin{aligned}
& j_{\mathrm{BO}}=\frac{1+\gamma}{\gamma} C_{\mathrm{p}} N_{\mathrm{T}} \times \\
& \quad \times \exp \left(-\frac{\beta}{2} \chi_{\mathrm{p}}^{1 / 2} \delta\right) \exp \left(u_{\mathrm{n}}-E_{\mathrm{G}} / k T\right)
\end{aligned}
$$

or, according to (6) and (10),

where

$$
j=j_{\text {MO }} \exp \left(u_{\mathrm{I}}\right)
$$

$j_{\text {MO }}=(1+\gamma) C_{\mathrm{n}} N_{\mathrm{T}} \exp \left(-\frac{\beta}{2} \chi_{\mathrm{n}}^{1 / 2} \delta-\psi_{\mathrm{ms}}\right)$.

Hence the $\mathrm{SiO}_{2}-\mathrm{Si}$ interface is depleted or inverted for the range of $j$ we are dealing with, and accordingly, the $F$-function can be approximated by

$$
F\left(u_{\mathrm{s}}, \xi_{\mathrm{s}}\right)=\left\{-u_{\mathrm{s}}+\alpha \exp \left(\xi_{\mathrm{s}}-u_{\mathrm{s}}\right)\right\}^{1 / 2}
$$

where $\alpha=p_{\mathrm{v}} / n_{\mathrm{v}}$ is the relation between the hole and electron concentrations in the base bulk.

The surface potential expression is obtained from (9), (12) and the neutrality equation (3), yielding

$$
u_{\mathrm{s}}=\alpha \frac{j}{j_{\mathrm{BO}}}-a \ln ^{2}\left(\frac{j}{j_{\mathrm{MO}}}\right)
$$


where

$$
a=\left(\frac{L_{\mathrm{D}} \varepsilon_{\mathrm{I}}}{\delta \varepsilon_{\mathrm{s}}}\right)^{2}
$$

Consequently, substituting the insulator and surface potentials, obtained respectively from (12) and (14), in the device voltage (Eq. 7), the $j-V$ expression is found :

$$
u_{\mathrm{A}}=a \ln ^{2} J+(n+1) \ln J-b J+c
$$

where the normalized current density $J$ is given by

$$
J=j / j_{\text {MO }}
$$

$n$ is the p-n junction ideality factor and

$b=\gamma \frac{N_{\mathrm{v}}}{N_{\mathrm{c}}} \frac{C_{\mathrm{n}}}{C_{\mathrm{p}}} \exp \left\{-\frac{\beta}{2}\left(\chi_{\mathrm{n}}^{1 / 2}-\chi_{\mathrm{p}}^{1 / 2}\right) \delta+u_{\mathrm{n}}-\psi_{\mathrm{ms}}\right\}$

$N_{\mathrm{c}}$ and $N_{\mathrm{v}}$ being respectively the effective densities of states in the conduction and valence bands of the semiconductor and

$$
c=u_{\mathrm{n}}-\psi_{\mathrm{ms}}+n \ln \frac{j_{\mathrm{MO}}}{j_{\mathrm{jo}}}
$$

$j_{\mathrm{jo}}$ being the p-n saturation current density.

For sake of clarity, we remark that the $u_{\mathrm{A}}(j)$ equation is not valid when the $\mathrm{SiO}_{2}-\mathrm{Si}$ interface is degenerated, the degeneration condition being

$$
\frac{E_{\mathrm{G}}}{k T}-u_{\mathrm{n}}-\ln \frac{j}{j_{\mathrm{BO}}} \leqslant 0 .
$$

An example of the $j-V$ characteristic obtained from equation (16) is represented in figure 2.

As a consequence of the $j-V$ characteristic, we can deduce the switching current density. Hence

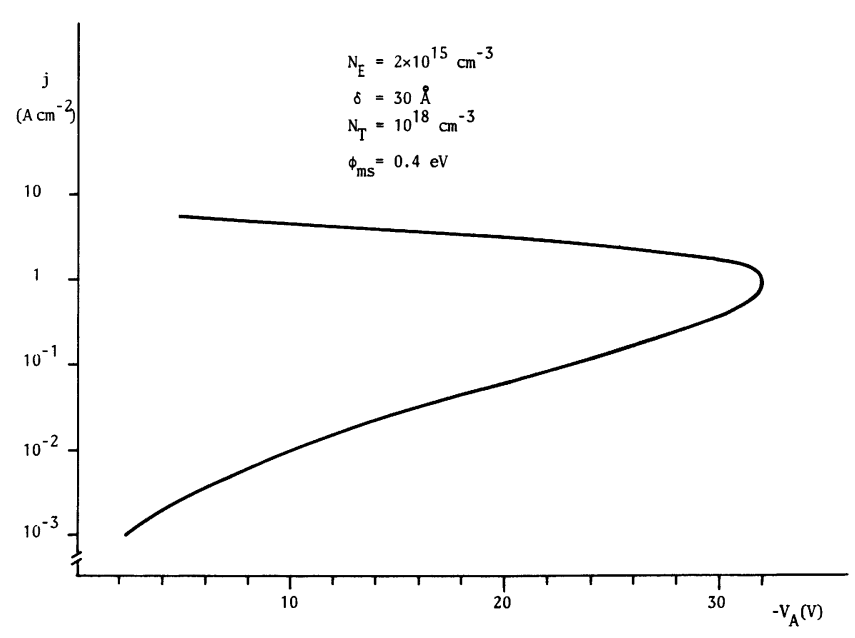

Fig. 2. - The $j-V$ characteristic according to resonant tunnelling formulation. Structure parameters : $N_{\mathrm{E}}=2 \times$ $10^{15} \mathrm{~cm}^{-3}, N_{\mathrm{T}}=10^{18} \mathrm{~cm}^{-3}, \phi_{\mathrm{ms}}=0.4 \mathrm{eV}$ and $\delta=30 \AA$. $\mathrm{d} u_{\mathrm{A}} / \mathrm{d} j=0$ at the switching point and, according to (16), the switching current verifies the following equation :

$$
M \ln J^{\mathrm{s}}-J^{\mathrm{s}}+N=0
$$

where $J^{s}$ is the normalized current density at the switching point. $M$ and $N$ are given by

$M=\frac{2 a}{b}=\frac{k T}{q^{2}} \frac{\varepsilon_{\mathrm{I}}^{2}}{\varepsilon_{\mathrm{s}} \delta^{2}} \frac{1}{\gamma} \frac{C_{\mathrm{p}}}{C_{\mathrm{n}} N_{\mathrm{v}}} \times$

and

$$
\times \exp \left\{\frac{\beta}{2}\left(\chi_{\mathrm{n}}^{1 / 2}-\chi_{\mathrm{p}}^{1 / 2}\right) \delta+\psi_{\mathrm{ms}}\right\}
$$

$$
\begin{aligned}
N=\frac{n+1}{b} & =\frac{n+1}{\gamma} \frac{C_{\mathrm{p}}}{C_{\mathrm{n}}} \frac{N_{\mathrm{E}}}{N_{\mathrm{v}}} \times \\
& \times \exp \left\{\frac{\beta}{2}\left(\chi_{\mathrm{n}}^{1 / 2}-\chi_{\mathrm{p}}^{1 / 2}\right) \delta+\psi_{\mathrm{ms}}\right\} .
\end{aligned}
$$

These two coefficients as well as the physical solutions of (21) are always positive. The diagram of figure 3 gives us information about the solutions of (21) in terms of the coefficients $M$ and $N$.

Obviously we are interested in solutions $J^{\text {s }}>1$ since the approximation performed on equations (8) and (9) are not longer valid for $J^{s}<1$.

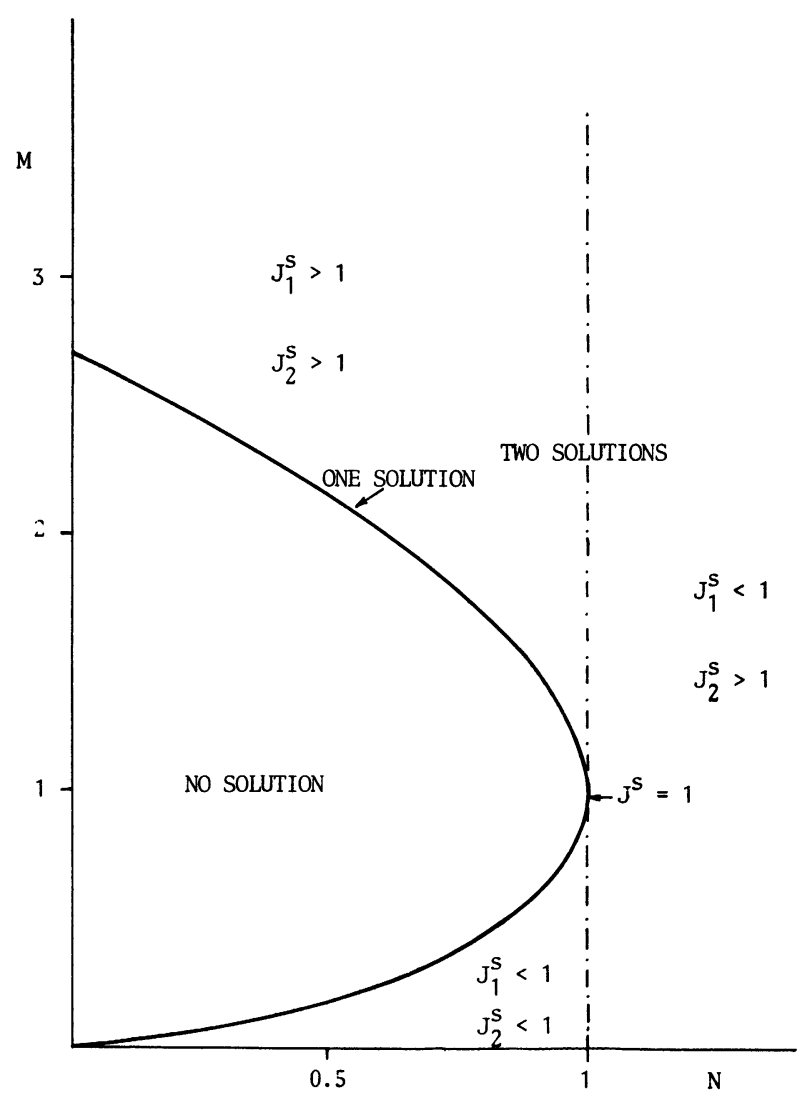

Fig. 3. - The solutions of equation (21) as a function of $M$ and $N$. 
The series sum

$$
J^{s}=N+M \ln \{N+M \ln (N+M \ln \ldots
$$

is the solution $J_{1}^{\mathrm{s}}>1$ of equation (21) when $N>1$, this value of $N$ being usual within the range of the insulator thickness $\delta$ we are dealing with. The sum converges quickly for the values of $N$ and $M$ we are using, resulting in the normalized current density at the switching point.

Once the switching current is obtained from (24), the switching voltage can be deduced from the $j-V$ characteristic of equation (16).

In the framework of this analytical model, the influence of the structure parameters on the switching behaviour is easily found and, therefore, one can verify the physical mechanisms involved in the device behaviour.

4. Conclusions. - A closed-form expression for the $j-V$ characteristic of the MISS device is obtained from the mathematical formulation of a regenerative model based on the resonant tunnelling conduction through the insulator.

From this $j-V$ expression both switching current and voltage are found. Besides, it allows to determine the influence of the structure parameters on the switching behaviour.

\section{References}

[1] El-Badry, A. and Simmons, J. G., Solid State Electron. 20 (1977) 963.

[2] Simmons, J. G. and El-BadRY, A., Solid State Electron. 20 (1977) 955.

[3] Sarrabayrouse, G., Thèse d'Etat (Sciences). Université Paul Sabatier, Toulouse, France (1978).

[4] Habib, S. E.-D. and Simmons, J. G., Solid State Electron. 22 (1979) 181.

[5] Habib, S. E.-D. and Simmons, J. G., Solid State Electron. 23 (1980) 497.

[6] Adan, A. and Zolomy, I., Solid State Electron. 23 (1980) 449.

[7] Millán, J., Serra-Mestres, F. and Buxó, J., Revue Phys. Appl. 14 (1979) 921.
[8] Chik, K. C. and Simmons, J. G., Solid State Electron. 22 (1979) 589.

[9] Buxó, J., Owen, A. E., Sarrabayrouse, G. and SebaA, J. P., Revue Phys. Appl. 13 (1978) 767.

[10] Millán, J., Ph. Thesis, Universidad Autónoma, Bellaterra Barcelona, Spain (1981).

[11] Millán, J., Serra-Mestres, F. and Aymerich-Humet, X., 11th European Solid State Device Research Conference ESSDERC 81, Toulouse, France (1981).

[12] Aymerich-Humet, X. and Serra-Mestres, F., Phys. State Solid (a) 51 (1979) 583 ; 54 (1979) 655.

[13] SzE, S. M., Physics of semiconductor devices (J. Wiley, New York) 1981. 